\author{
ANETTA BRECZKO \\ (Białystok) \\ AGATA BRECZKO \\ (México City)
}

\title{
LA CULTURA DEL DERECHO EUROPEO Y EL MULTICULTURALISMO. DESAFÍOS PARA LA DEMOCRACIA EN EL SIGLO XXI
}

\section{El multiculturalismo - algunas consideraciones introductorias}

La cultura, en términos más generales, puede ser entendida como el legado social de la humanidad. A su vez, es identificada como una forma de vivir organizada, fundamentada en un entorno común. ${ }^{1}$ Comprende la actividad humana que se traduce en la llamada "herencia cultural". Tal herencia se compone, por un lado, de bienes materiales y, por el otro lado, de bienes inmateriales (p.ej.: ideales, valores, principios, entre otros). Dicho de otro modo, el legado cultural es, básicamente, todo lo que el hombre es y lo que posee. ${ }^{2}$

Las sociedades europeas contemporáneas se caracterizan por su pluralismo. En este contexto, la imposición cultural se convierte en un proceso cada vez más intenso, dinámico y visible. Este último lleva a que los componentes y elementos típicos de una cultura sean retomados por otras. Se da, entonces, la recepción de los modelos y patrones culturales ajenos. Al mismo tiempo, puede observarse un proceso de aculturación, en el cual las sociedades esencialmente distintas entran en relaciones e interacciones muy cercanas, muchas veces conflictivas. Ello es acompañado por el fenómeno de sincretismo cultural y se refleja en la transformación de elementos de culturas genética y geográficamente lejanas en unidades

\footnotetext{
1 P. Bagby, Pojęcie kultury, [en:] F. Adamski (coord.), Człowiek. Wychowanie. Kultura. Wybór tekstów, Cracovia 1993, p. 165.

2 C. Dawson, Istota kultury, [en:] F. Adamski (coord.), op. cit., p. 176.
} 
relativamente homogéneas. ${ }^{3}$ Tales procesos, hoy en día, son muy característicos de los países pertenencientes al círculo de la civilización europea; se traducen e influyen considerablemente en la definición del rumbo que toma la evolución de la cultura jurídica, la cual "coloca" al derecho entre los demás componentes de la cultura. ${ }^{4}$

Como bien nota R. Tokarczyk, "El concepto particular de la cultura del derecho europeo se ha convertido en un elemento crucial para la definición [en términos más generales] de la cultura jurídica del Occidente. Al conceptualizar la noción relativamente ambigua del 'Occidente' y su sentido cultural, asumimos que la cultura jurídica occidental se ha conformado en una unidad sincrética, compuesta por elementos de la antigua cultura griega, romana y judeocristiana." 5 Sus símbolos más emblemáticos son: el Acrópolis, la Colina Capitolina y el Calvario. La cultura jurídica europea está definida sobre una base ideológica concreta que, de manera fundamental, moldea sus valores. Éstos, a su vez, forjan la vida humana misma: las actividades cotidianas y las relaciones sociales e interpersonales. Igualmente, los valores influyen en el funcionamiento de los poderes gubernamentales, la legislación y la ejecución de las leyes, así como la estructura del Estado y los vínculos entre las autoridades y los ciudadanos. "Dicho en unas pocas palabras, los ideales civilizatorios, como valores humanos universales, le dan sentido a la existencia del Estado democrático y de derecho." 6 Recopilando, el entendimiento del derecho como un fenómeno cultural permite reconocer que las normas jurídicas también son normas sociales que reflejan valores generalmente aceptados e internamente "normalizados" en una sociedad concreta. ${ }^{7}$

Vale la pena subrayar que, en las situaciones donde emerge la confrontación entre mundos radicalmente diferentes, de manera necesaria se crean y recrean conflictos y tensiones. Así, en el lugar de la certeza y notoriedad, aparece la necesidad de contrapner los sistemas de valores diversos, distintos y, en muchas ocasiones, rivales. ${ }^{8}$ La sensación de la libertad - prometida e impulsada por las democracias contemporáneas -, se convierte entonces en una sensación de incertidumbre e inseguridad crecientes, cada vez más características de las sociedades

3 R. Tokarczyk, Wspólczesne kultury prawne, Varsovia 2012, 49-51 pp.

4 Ibidem, p. 92.

5 Ibidem, p. 193.

6 B. Jastrzębski, O funkcjach ideałów w zasadach demokratycznego państwa prawa, [en:] A. Kryniecka (coord.), Dzisiejsze znaczenie idealów, Varsovia 2015, p. 19.

7 A. Drewniak, Wartości perfekcjonistyczne z perspektywy prawa, [en:] S. Wronkowska (coord.), Polska kultura prawna a proces integracji europejskiej, Cracovia 2005, p. 223.

8 A. Breczko, Wielokulturowość jako źródto dylematów moralnoprawnych $w$ demokratycznych państwach prawa, [en:] M. Andruszkiewicz, A. Breczko, S. Oliwniak (coords.), Filozoficzne i teoretyczne zagadnienia demokratycznego państwa prawa, Białystok 2015, 29-44 pp. 
contemporáneas. ${ }^{9}$ En las condiciones del pluralismo, todo aquello que hasta ahora ha sido tratado como "normal" y "notorio", desde la perspectiva de los sistemas morales, hoy en día está puesto en entredicho, cuestionado e, incluso, rechazado. Así, el criterio último en la elección de los valores y las normas es el individuo autónomo.

El multiculturalismo es un caso muy peculiar dentro de los procesos de transformación y "negociación" de la identidad (o identidades) en el mundo occidental. El individuo moderno vive en un "mundo de elecciones", absolutamente inevitables dentro de las sociedades ideológicamente distintas. Dichas elecciones atañen, entre otras cosas, a los valores. El orden moral tradicional que, históricamente, regía al conjunto de la sociedad, ahora desaparece paulatinamente. Frente a la diversidad de las normas y maneras de vivir, la construcción de la identidad moral se vuelve una tarea sumamente compleja. La moral pierde su poder integrativo y de unificación; deja de ser la base para la cohesión social. Dicho de otro modo, desaparece, poco a poco, un punto de referencia "supremo" que solía unir, desde arriba, a los individuos distintos. Toda la cultura occidental adquiere rasgos cada vez más individualistas, impulsando la libertad y la independencia privadas. ${ }^{10}$ Los sociólogos frecuentemente describen la época contemporánea como un tiempo de "vínculos débiles". La versión actual de la modernidad, que define al mundo como una "aldea global", es: "borrosa", "líquida", "dispersa", "amorfa" y "desregulada". 11

El hombre moderno es un hombre en constante movimiento. Los medios de comunicación y, en particular, las nuevas tecnologías de la información le permiten "participar" y penetrar en diversas culturas a la vez, sin siquiera tener que salir de su casa. No obstante, "lejos de homogenizar la condición humana, la anulación tecnológica de las distancias de tiempo y espacio tiende a polarizarla [cursivas del autor]. Emancipa a ciertos humanos de las restricciones territoriales a la vez que despoja al territorio, donde otros permanecen confinados, de su valor y su capacidad para otorgar identidad." ${ }^{12}$ Lo anterior advierte de la existencia de diversas amenazas y numerosos riesgos relacionados con la disfuncionalidad del sistema democrático que, a su vez, están desestabilizando los estándares y las reglas democráticas que han regido por siglos. ${ }^{13} \mathrm{~A}$ pesar de ello, la idea del multiculturalismo se ha convertido en un rasgo ya inherente a las sociedades europeas

9 Z. Bauman, Zindywidualizowane spoleczeństwo, Gdańsk 2008, p. 194.

10 A. Giddens, Socjologia, Varsovia 2012, 583-584 pp.

11 Z. Bauman, Plynna nowoczesność, Cracovia 2006, p. 231.

12 Z. Bauman, La Globalización: Consecuencias Humanas, México 2001, p. 28.

13 Ł. Kierznowski, Demokracja a wielokulturowość - postawa państwa demokratycznego wobec wspólczesnych zmian spolecznych, "Drohiczyński Przegląd Naukowy. Wielokulturowe Studia Drohiczyńskiego Towarzystwa Naukowego" 2014, núm. 6, 153-154 pp. 
y, en algunos casos, incluso en el fundamento de las mismas. Se sigue aceptando que la gran diversidad de las culturas - que representan, respectivamente, valores irrepetibles y únicos - constituye per se un bien común y complementario de toda la humanidad, mientras que el etnocentrismo es visto como reflejo de un primitivismo cultural. Al mismo tiempo, tanto en la práctica como en la teoría, el concepto de las sociedades multiculturales está afrontando una crisis, sufriendo incluso algunos fracasos. Hace falta una política gubernamental coherente y apropiada, que sea capaz de proteger a los diversos grupos étnicos y culturales, así como ofrecer instrumentos que permitan eliminar las consecuencias indeseables y negativas derivadas del multiculturalismo (como, p.ej. el extremismo o, incluso, terrorismo).

La teoría desarrollada por S. Huntington a principios de la década de los años noventa resulta ser una herramienta útil para entender el mundo contemporáneo y la complejidad e interdependencia entre sus tan diversas culturas. El autor intuyó que los futuros conflictos habrían de desarrollarse no tanto entre los estados, sino más bien entre civilizaciones. En este caso, la religión sería el elemento central y definitorio de estas últimas. Igualmente, Huntington predijo que las diferencias culturales, derivadas de las divisiones o sub-divisiones religiosas, pudieran convertirse en el motor principal de las guerras. Asimismo, percibió que el mundo contemporáneo se va convirtiendo en la arena de lucha y rivalidades entre las civilizaciones principales (trátese de la occidental, islámica y china). ${ }^{14}$ Huntington suponía que las diferencias entre estas últimas son tan cruciales que, incluso ante el peso del proceso de la globalización, no podrían ser borradas. En la situación donde la cultura o el lenguaje de algunas civilizaciones ceden ante la presión de la civilización dominante, entonces la religión y, sobre todo, sus fracciones más extremistas, fungen como directrices. Así, la religión adquiere la función de una suerte de "identificador" dentro del ámbito de una civilización dada. ${ }^{15}$ Son justamente los valores religiosos los que definen lo que es bueno y lo que es malo - desde la perspectiva de sus dogmas respectivos - y, por tanto, moldean el carácter de las sociedades correspondientes. Por esta razón, a veces parecen ser "indiscutibles" e "irreversibles". 16

Actualmente, podemos tener la impresión de que las "profecías" de Huntington se están cumpliendo. Hoy en día, el enfrentamiento y las tensiones entre los valores de la civilización Occidental y del Islam parecen particularmente palpables.

14 S. Huntington, Zderzenie cywilizacji i nowy ksztalt tadu światowego, Varsovia 2006, p. 56.

15 Ibidem, p. 16.

16 Ibidem, p. 107. 


\section{El multiculturalismo y el fundamentalismo religioso}

El ataque terrorista del 11 de septiembre de 2001 es, hasta cierto punto, la confirmación simbólica de la teoría sobre el "choque de las culturas".

Hoy en día, el extremismo, derivado de los ideales y dogmas religiosos o culturales, parece representar la fuente principal de las amenazas a la seguridad. Además, dentro de las lógicas y mecanismos del mundo contemporáneo, el terrorismo ha adquirido un sentido global. Las organizaciones terroristas más fuertes operan actualmente en los territorios de Siria, Turquía, Eritrea, Somalia, Nigeria y Malí, entre otros. Además, sus métodos se han vuelto cada vez más sofisticados y variados, superando los tradicionales "coches-bomba". Por ejemplo, los ataques más recientes, ideados y realizados por los fundamentalistas islámicos, implicaron el uso de los niños en los ataques suicidas; destacan, igualmente, la publicación y la difusión de las ejecuciones brutales por Internet y en las redes sociales, así como los ataques de carácter simultáneo en diversas partes del mundo (en Susa, Kuwait y Saint-Quentin-Fallavier), que logran sembrar miedo e inseguridad indistintamente, en todos los continentes.

Además de ello, en la época de la globalización, también los países democráticos han sufrido el gran alcance de los actos de terror. Para ofrecer algunos ejemplos, se puede mencionar el ataque de los fundamentalistas islámicos en el centro de negocios en Sydney o el ataque al periódico Charlie Hebdo en Francia.

En este sentido, con tal de penetrar mejor dentro del mundo occidental, los miembros de una fracción radical del Islam - los salafistas - se dedican, entre otras actividades, a reclutar a los ciudadanos europeos para el Yihad. Efectivamente, si bien se trata de un fenómeno todavía poco significativo en términos cuantitativos, un número cada vez mayor de los residentes de los países democráticos nutre las filas de los yihadistas. Curiosamente, muchos de estos neófitos provienen de las partes consideradas como las más desarrolladas del mundo: como Alemania o Dinamarca; asimismo, puede alarmar el hecho de que ya varios miles de estos militantes occidentales combaten, en verdaderas guerras, del lado de los islamistas (para dar un ejemplo, en el caso de Siria). ${ }^{17}$

Si bien los medios de comunicación suelen darle mayor énfasis a los excesos y la brutalidad de las acciones emprendidas por los fundamentalistas del Islam, así como, estadísticamente, "en la lista de Estados con las violaciones más graves de la libertad religiosa predominan los países musulmanes" ${ }^{18}$, el problema de dis-

17 Cfr. Miles de militantes occidentales se integral al Estado islámico, "El economista", 18 de septiembre 2014, http://eleconomista.com.mx/internacional/2014/09/18/miles-militantesoccidentales-se-integran-estado-islamico (15.06.2015).

18 Cfr. Informe Libertad Religiosa en el Mundo - 2014, p. 7, http://www.infovaticana.com/ wp-content/uploads/2014/11/Informe-AIN-2014.pdf (15.06.2015). 
criminación religiosa, sin duda alguna, no es unidireccional. En diversas partes del mundo, los comunmente conocidos "opresores" se convierten en víctimas, como sucede, por ejemplo, en Birmania o China, donde los musulmanes sufren fuertes persecuciones. Igualmente, tras la cruzada contra el terror, en los países democráticos (sobre todo en Europa, Estados Unidos e Israel), los musulmanes suelen ser confundidos y reducidos, por el simple hecho de profesar su religión, a terroristas o fundamentalistas islámicos. Ello conduce a su marginación, estigmatización e inseguridad, "bajo el peso de una amalgama de estereotipos y prejuicios" 19 .

Recopilando, los ejemplos de violencia por motivos étnicos y religiosos afloran en el mundo entero, en absolutamente todos los continentes: empezando por actos de discriminación e intolerancia "menores" (pero no por ello menos graves), y terminando en masacres y genocidios de gran alcance.

En particular, las autoridades de los países democráticos reaccionan de modos muy diversos a las amenazas que se presentan y que son consecuencia directa del fundamentalismo religioso. Para dar un ejemplo, en Dinamarca se está trabajando en una nueva ley que impida que sus ciudadanos puedan participar de manera voluntaria en las guerras civiles en Siria, Irak o Somalia. El proyecto de ley prevee prohibir cualquier intento de expresar la aprobación de las acciones terroristas, incluso a través de las redes sociales; por ejemplo, los comentarios publicados en facebook o twitter que aplaudan las reglas del Yihad, podrían ser sancionados incluso con la retención del pasaporte y la prohibición de salir del país.

Todo lo anterior es, en cierto modo, la prueba de que la idea misma del multiculturalismo sufre una crisis profunda. Tanto los gobiernos como los individuos parecen perder la fe en la real posibilidad de crear sociedades multiculturales que, por un lado, se basen en valores compartidos y universales y, por el otro lado y de manera paralela, respeten las particularidades de sus respectivas culturas.

\section{Las prácticas crueles en nombre de imperativos culturales}

Las reflexiones sobre la cultural defence ("defensa cultural" o "una defensa por cultura") giran alrededor de las siguientes preguntas: ¿si y hasta qué punto, en los países democráticos, los imperativos culturales pueden justificar los actos crueles y bárbaros (p.ej. las matanzas de honor y sacrificios rituales de animales, mutilación obligada de mujeres y niñas, etc.)?; En la época del multiculturalismo,

19 Cfr. A. Figueras, Los musulmanes en Europa, disciminados, "El Mundo", 24 de abril 2012, http://www.elmundo.es/elmundo/2012/04/24/internacional/1335254449.html (16.06.2015). 
¿debe de tolerarse - en nombre de la libertad de religión - las prácticas crueles realizadas por las minorías, totalmente opuestas, contrarias y ajenas a los paradigmas de la civilización occidental?

Empecemos por un asunto muy neurálgico que, sin duda, se deriva del multiculturalismo. ¿Cómo los juzgados deberían de tratar a los responsables de los llamados "asesinatos por honor", en algunas ocasiones cometidos por los representantes de las minorías que provienen de países, en donde tales actos son culturalmente legítimos y aceptados?

Los crímenes de honor son, en la mayoría de las casos, efectuados por la misma familia, motivada por la necesidad de "limpiar el deshonor" que cayó sobre la misma, por culpa de alguno de sus miembros. De acuerdo con el informe de The State of World Population, se estima que, al año, alrededor de 5 mil asesinatos de este tipo se cometen en todo el mundo. Las principales víctimas son mujeres; las causas de los mismos resultan muy diversas: p.ej. la elección de una pareja inadecuada, las relaciones sexuales prematrimoniales y fuera de matrimonio, el uso de ropa considerada como "inapropiada", las preferencias homosexuales, la violación, la conversión a otra relgión, entre muchos otros. A veces, basta con sospechar que una mujer cometió un acto incompatible con el código moral aceptado por la sociedad en cuestión.

Actualmente, la mayoría de los asesinatos de honor sucede en Asia (en la India, en Pakistán, Bangladés, Afganistán, Jordania, Turquía, Irak, Irán y Yemen), en África (p.ej. Maruecos, Egipto, Uganda), América del Norte (México, Estados Unidos y Candá) y América del Sur (p.ej. Brasil).

Los asesinatos de honor también llegan a ocurrir en Europa, sobre todo en el seno de las familias de inmigrantes, originarios de Pakistán, Bangladés y Kurdistán: de hecho, decenas de juicios por este tipo de crímenes se han llevado a cabo en los tribunales de Gran Bretaña. Asimismo, casos similares han sido registrados en Suecia, Albania, Kosovo e Italia.

Las diferentes perspectivas que la doctrina desarrolla sobre los asesinatos de honor conducen, frecuentemente, a un debate intenso sobre la ya mencionada cultural defence. Dicho concepto surge de una estrategia muy peculiar de defensa, usada sobre todo en los juicios de carácter penal y fundamentada en el derecho estadounidense. En grandes rasgos, la cultural defence lleva a la posible mengua de la responsabilidad del acusado de tal crímen, cuando se demuestra que sus acciones han sido motivadas por imperativos culturales concretos. ${ }^{20}$

Ya en los inicios de la década de los años ochenta del siglo XX, los tribunales norteamericanos se han enfrentado con la necesidad de resolver varios casos,

20 A. Breczko, op. cit., p. 37. 
en los cuales las partes pertenecían a minorías étnicas y nacionales. Si bien los hechos de los que se les inculpaba no eran compatibles con el marco legal existente, éstos encontraban cierta justificación en los usos y costumbres de dichas minorías. Entre estos casos, los anteriormente definidos asesinatos de honor eran muy frecuentes. Por lo general, se trataba de la muerte de las esposas que traicionaban a sus maridos. Uno de los procesos más famosos y sonados fue, sin duda, el de un ciudadano americano de origen chino. ${ }^{21} \mathrm{El}$ tribunal, al sentenciarlo, tomó en consideración los elementos culturales. Cabe mencionar que, en la tradición china, la traición por parte de la esposa es particularmente humillante para el hombre quien, en numerosas ocasiones, queda incapacitado para contraer el matrimonio nuevamente: similares circunstancias han sido tomadas en cuenta a favor del acusado.

En otras ocasiones, se han presentado acusaciones por asesinato, derivado de un intento fallido de suicidio por honor. Tal fue el sonado caso de una japonesa que, al averiguar que su marido tenía una amante, intentó suicidarse, ahogándose en el océano junto con sus dos pequeños hijos. Si bien la mujer sobrevivió, no se pudo salvar a los niños. ${ }^{22}$ Frente a tal situación, el juzgado de California tomó en consideración una petición firmada por miles de ciudadanos pertenecientes a la minoría japonesa. Aquí, nuevamente, el argumento de la cultural defence tuvo un peso importante en la balanza, llevando, en consecuencia, a una sentencia menos severa. ${ }^{23}$

De igual manera, en Polonia también hay registro de un asesinato por honor. Precisamente, se trata del caso de Naeem Abbas: un pakistaní que fue sentenciado, en 2009, a 15 años de prisión por haber matado a su esposa - ciudadana polaca. La mujer huyó del marido. A lo largo del proceso, el acusado estaba justificando su delito con el motivo de karo-kiri, o asesinato por honor. En este sentido, el hecho de que la mujer escapara del "poder de su esposo", lo llevó a sentir un imperativo moral de castigarla de esta manera. Si bien en el derecho polaco no existe ninguna ley que permita ajustar la sentencia por el asesinato, en función de los usos y constumbres ajenas, el tribunal de Polonia, por primera vez en su historia, oficialmente aceptó que, según la sharia, la mujer es culpable y merece morir si: habla con otro hombre o es violada por alguien que no pertenece a su familia; de manera constante y con obstinación se rehusa a cubrirse el rostro o el

21 N.A. Gordon, The Implications of Memetics for the Cultural Defence, "Duke Law Journal" 2001, vol. 50, p. 1813.

22 M.P. Golding, The Cultural Defence, "Ratio Juris" 2002, vol. 15, núm. 2, 145-150 pp.

23 S. Sykuna, Filozofia prawa a multikulturalizm - studium pewnego przypadku, [en:] D. Bunikowski, K. Dobrzeniecki (coords.), Pluralizm prawny, tradycja, transformacje, wyzwania, Toruń 2009, p. 201. 
cabello; expresa la voluntad de abandonar a su esposo, o intenta huir del mismo, renunciando así al modelo de la familia pakistaní. ${ }^{24}$

Otro desafío para los sistemas normativos democráticos - también fruto del multiculturalismo - es el problema de las mutilaciones rituales. Resulta que, con el proceso del melting pot (o crisol de razas), estos usos y tradiciones también han llegado al continente europeo.

La costumbre de la circuncisión de las niñas es muy común entre los diversos pubelos del Medio Oriente, así como en algunos países africanos (p.ej. Somalia), de América del Sur y Sud-Este Asiático. Asimismo, este tipo de usos también aparecen en Australia y algunas islas del Pacífico. El fundamento que, supuestamente, legitima tales parácticas, se sustenta en el imperativo relgioso de "pureza moral".

El aumento del número de niñas que están en el riesgo de sufrir las mutilaciones rituales, incluso en las democracias europeas - se estima que puede tratarse incluso de medio millón de mujeres - se debe al creciente número de migrantes que son originarios de los países, en donde este tipo de prácticas constituye un elemento inherente a la cultura. Durante largos períodos de tiempo, dada la "sensibilidad a las diferencias culturales", las autoridades no reaccionaban frente a los casos de circuncisión ritual de mujeres.

En Europa, estas prácticas han sido prohibidas por primera vez en Suecia (desde 1982) y, posteriormente, en Gran Bretaña (desde 1985). Asimismo, desde 1999 y 2003, respectivamente, los tribunales suecos y británicos pueden perseguir a personas residentes que salen del país, explícitamente con el fin de realizar dicho ritual con sus hijas o familiares. En este mismo sentido, ya ha habido casos de sentencias severas, incluso de privación de libertad y multas sumamente altas: los tribunales, por lo general, han acordado que la circuncisión obligada de niñas es sinónimo de tortura. Leyes similares han entrado en vigor en Austria, Bélgica, Dinamarca y España. De igual forma, las autoridades de Finlandia, Alemania, Irlanda, Italia, Luxemburgo, Portual y Holanda usan el derecho común para prevenir la circuncisión de las niñas.

Recapitulando, la introducción de impedimientos y barreras legales contra la circuncisión ritual, así como las sentencias cada vez más severas contra este tipo de prácticas son una clara señal de que las sociedades occidentales no están dispuestas a aplaudir costumbres crueles, aceptadas en otras culturas y "traídas" hacia las democracias europeas a través de los flujos migratorios.

Por último, las matanzas rituales constituyen otro problema delicado, engendrado en el contexto del multiculturalismo; los debates en torno a esta problemática ilustran el estado de la "condición moral" de las sociedades occidentales

24 Zabójstwo honorowe w Polsce, "Duży Format. Dodatek do Gazety Wyborczej", 3.04.2014. 
en el siglo XXI. Puede resultar sorprendente que, en los tiempos contemporáneos, todavía se practique las ofrendas de animales. Evidentemente, las matanzas rituales son únicamente la metafórica "punta del iceberg" de los problemas que surgen de la manera en que, hoy en día, las personas tratan a otros seres vivos. En efecto, se puede incluso cuestionar si, en la era de la ganadería y agricultura intensivas, es posible hablar de procedimientos de matanza "humanitaria" de los animales. ${ }^{25}$

Resulta que la matanza, que esté acorde con la tradición europea del manejo de animales - que tiende a minimizar en lo posible su sufrimiento - no cumple los "requisitos" del Islam y Judaísmo. A la luz de las reglas de ambas religiones, sus creyentes únicamente pueden consumir carne proveniente de los animales sacrificados, sin haber sido aturdidos previamente. La matanza ritual (Shojet en el Judaísmo y dhabihah en el Islam) consiste en que el animal muere por desangramiento, con el importante detalle de que, al inicio del procedimiento, éste está totalmente consciente de lo ocurrido. Si bien los creyentes de las arriba mencionadas religiones sostienen que la muerte en el rito es una opción verdaderamente humanitaria, en realidad ésto pudiera aplicar únicamente en los casos de las matanzas a pequeña escala, en la granja, y no a nivel de mataderos industriales.

El aturdimiento de los animales se introdujo en Europa por razones humanitarias; con tal de disminuir el sufrimiento de los sacrificados. Así, dicha práctica se ha convertido en un requisito exigido por la ley en los mataderos de numerosos países, sustentado en la opinión de la mayoría de los expertos y especialistas del ámbito de la zootecnia y veterinaria. En el terreno del derecho europeo, se ha empezado a considerar a los animales como seres capaces de sentir dolor y angustia, dignos de respeto y cuidados. En este sentido, la obligación de "aturdir antes de sacrificar" es resultado de cierta evolución, tanto en el derecho como en las percepciones humanas, que llevaron a tratar a los animales como seres sintientes y sensibles; ello también encuentra su sustento en la teoría ética contemporánea que considera que el bienestar de los animales constituye una categoría moral. ${ }^{26}$

En el caso particular de Polonia, hasta 2012, la matanza ritual era admisible en virtud de la disposición del Ministro de Agricultura y Desarrollo Rural de 2004. En noviembre de 2012, el Tribunal Constitucional reconoció que la mencionada disposición era incompatible con la ley sobre la protección de los animales, la cual prohibía explícitamente el sacrificio sin aturdimiento previo. Desde enero de 2013,

25 Cfr. A. Breczko, Od rzeczy do podmiotu, czyli praktyczne implikacje etyki ochrony zwierzat, "Białostockie Studia Prawnicze" 2013, núm. 14, p. 23.

26 Cfr. D. Probucka, Filozoficzne podstawy idei praw zwierzat, Cracovia 2013; J. Woleński, Podmiotowość zwierzat $w$ aspekcie filozoficznym, [en:] T. Gardocka, A. Gruszczyńska (coords.), Status zwierzęcia. Zagadnienia filozoficzne i prawne, Toruń 2012, 13-27 pp. 
dicha disposición perdió efectos legales, coincidiendo, en paralelo, con la entrada en vigor de una nueva disposición, esta vez comuinitaria, que permite evadir el proceso de aturdimiento en los mataderos, en el caso de las matanzas rituales. No obstante, la nueva ley de la Unión Europea no obliga a ningún país miembro a hacer uso de esta posibilidad: los reglamentos nacionales pueden apoyar una mayor o menor protección de los animales durante el proceso de su muerte.

En este caso, las enmiendas a la ley polaca de protección de los derechos de animales, en la cual se prohibió definitivamente la matanza ritual, han tendio que afrontar serias protestas por parte de las organizaciones judías internacionales e, incluso, responder a las acusaciones por antisemitismo. Los musulmanes también han protestado. Finalmente, bajo dichas presiones, el Tribunal Constitucional de Polonia ha permitido la matanza ritual en diciembre de $2014^{27}$. Ello implica que los animales, nuevamente, pueden ser sacrificados sin aturdimiento, incluso a escalas grandes: industrial y para exportación. El Tribunal, tras su dictamen, subrayó el carácter "litúrgico" de tal actividad, sin importar el número de los animales en cuestión.

Ante estos hechos, se puede constatar que el "examen de moralidad" no ha sido aprobado; ganaron los intereses particulares y, podemos sospechar, Polonia pronto se podrá convertir en el "matadero ritual" del mundo, o por lo menos de Europa. Después de todo, bajo el conveniente pretexto de ser políticamente correcto y en el nombre del multiculturalismo, la tolerancia religiosa y la prosperidad económica de algunos sectores, se han abierto las puertas para el sufrimiento injustificado de los "seres sintientes".

Aquí cabe preguntar ¿hasta qué punto la libertad de religión es un "valor absoluto"? Parece más lógico y más justificado que el derecho de realizar mantanzas rituales fuera limitado, más bien, por los valores de la moral pública dominante. Desafortunadamente, nuestra civilización todavía, por mucho tiempo, no podrá arreglárselas sin matar y explotar animales. No obstante, se debería - siguiendo el ejemplo de otros países europeos (como Suecia o Dinamarca) - evitar, en lo posible, causarles dolor y sufrimiento infundados e innecesarios. Aun guardando todo el respeto hacia las creencias religiosas o culturales ajenas, éstas no pueden ni deben presionar al legislador de derecho polaco para legalizar la crueldad; y, aún menos, cuando la justificación de mayor peso se reduce a maximizar las ganancias. Todas las prácticas bárbaras y feroces, sin importar cuán arraigadas estén en la tradición, deberían de ser suprimidas de la vida social. Tal vez tengan la razón aquellos que sostienen que, hasta que no se elimine la atrocidad e insensibilidad hacia los animales, persistirá también la crueldad de un hombre hacia otro hombre.

27 K 52/13. 


\section{El multiculturalismo y el futuro de la institución de matrimonio y de la familia}

El fin último de la institución del matrimonio ha sido, por siglos, crear las condiciones necesarias para darle vida y criar a las nuevas generaciones. ${ }^{28}$ Una familia tradicional - la denominada "familia núclear" - solía estar compuesta por una pareja heterosexual y los hijos. ${ }^{29}$

En las sociedades actuales - en constante movimiento y sumamente plurales - se ha vuelto cada vez más visible la diversidad de las costumbres humanas en torno al matrimonio y la familia. ${ }^{30}$ En la historia humana, hay registro de numerosas y muy variadas formas de unión formal entre las personas: empezando por la monogamía, aún la más común, pasando por las poliginia y poliandria, y terminando en matrimonios multilaterales (grupales). La poliginia ha sobrevivido hasta la actualidad, persistiendo todavía en algunos países africanos (p.ej. Egipto). Igualmente, la poliandria aún se practica, por ejemplo, en la India y en Tibet. En cuanto a los matrimonios multilaterales, éstos se realizan todavía entre los indígenas de América del Sur, en el norte de Alaska (entre los Innu) y en el centro de Australia, entre otros. ${ }^{31}$

La aceptación casi universal de la monogamia puede considerarse, en parte, como resultado del progreso civilizatorio y de las consecuentes adaptaciones sociales, económicas y religiosas. La tradición judeocristisana ha promovido (y aún hoy en día sigue promoviendo) la llamada "monogamia cerrada", que no acepta nignún tipo de relaciones sexuales fuera de matrimonio. ${ }^{32}$ En las sociedades occidentales, las muy diversas formas de relaciones de otro tipo han sido eliminadas casi por completo, desapareciendo de la vida social por siglos, bajo la influencia, a veces ferréa, del cristianismo.

Desde algunas décadas, es posible observar la aparente crisis del modelo tradicional de la familia nuclear. Ello, en parte, es la incuestionable consecuencia de los cambios civilizatorios. ${ }^{33}$ En muchos países, a partir de la segunda mitad del

28 S. Shell, The Liberal Case Against Gay Marriage, „The Public Interest” 2004, núm. 156, p. 7.

29 A. Toffler, Trzecia fala, Varsovia 1986, 260-261 pp.

30 J. Bront, B. Nowacka, Różnorodność związków matżenskich na świecie, Krynica Morska 2008 , p. 8.

31 A. Lewandowska, Nieprzeciętność a formy malizeństw i demokracja, [en:] M. Szyszkowska, A. Rossmanith (coords.), Nieprzeciętność. Dylemat wolności, Varsovia 2013, 163-171 pp.

32 Ibidem, p. 164.

33 Cfr. A. Breczko, S. Oliwniak, Biopolitics, ethics and the culture of lawfulness. Implications for the next generation?, [en:] H. Kury, S. Redo, E. Shea (coords.), Women and Children as Victims and Offenders, Background, Prevention, Reintegration. Suggestions for Succeeding Generations, Springer 2015. 
siglo XX, la institución del matrimonio se ha vuelto, paulatinamente, cada vez más inestable y frágil; paralelalmente, ha crecido el interés hacia el concubinato. Igualmente, la disminución en el número de los matrimonios contraídos ha sido acompañada por el sucesivo incremento de los divorcios. Dicho de otro modo, la institución tradicional de matrimonio ha entrado en su fase decadente. ${ }^{34}$ Lo anterior se debe a muy diversos factores: como sostiene A. Toffler, para rescatar a la "familia tradicional" o "nuclear", habría que, primero, "destruir las computadoras, bloquear el desarrollo de los servicios y los medios de comunicación masiva, volver a mandar a las mujeres a la cocina, disminuir el salario de los jóvenes trabajadores, con tal de hacerlos depender aún más - y por más tiempo - de su familia, prohibir los anticonceptivos y disminuir la esperanza de vida de toda la población." 35

Al tomar en consideración el abanico entero de las formas de matrimonio y, a la vez, la crisis del matrimonio nuclear, suele señalarse, con cada vez mayor frecuencia, que dicha institución debería de ser neutra: en cuanto se trate del número de las personas que quisieran formar la unión y en cuanto al sexo de las mismas. 36

Por otro lado, el debate sobre la necesidad de legalizar la poligamia en los países democráticos inició, ya hace unos años, en Canadá. La lucha por tener, legalmente, varias esposas fue iniciada por los mormones de la ciudad de Bountiful, cerca de la frontera con los Estados Unidos. Éstos subrayaban que la poligamia es el fundamento mismo de su religión, la cual los obliga a tener, como mínimo, tres mujeres. De otro modo, su posibilidad de ir al paraíso sería nula. Los mormones estuvieron de acuerdo en que la libertad de religión, bien asegurada por la Constitución canadiense, les otorga el derecho de optar por el modelo de familia de su preferencia. Como parte de la respuesta, en noviembre de 2014, el Ministro de Ciudadanía e Inmigración de Canadá, Ch. Alexander, presentó un proyecto de reforma que, entre otras cosas, pretende prohibir la residencia en el país de los migrantes que practiquen la poligamia. Hasta ahora, a pesar de los pronósticos de los medios, Canadá todavía no se ha convertido en la primera democracia que, en nombre de la libertad de culto, legalice este tipo de relaciones múltiples. Al contrario, las autoridades han tachado algunas de las costumbres de las minorías religiosas como una serie de "prácticas culturales bárbaras".

34 F. Fukuyama, Wielki wstrząs. Natura ludzka a budowa porzadku spolecznego, Varsovia 2000, 42-51 pp.

35 A. Toffler, op. cit., p. 260.

36 Cfr. A. Breczko, O potrzebie redefinicji pojęć „matżeństwo” $i$ „rodzina” we wspólczesnym pluralistycznym świecie (w kontekście rozważań na temat związów partnerskich), [en:] "Miscellanea Historico-Iuridica" 2014, vol. XIII. 
Las relaciones poligámicas de los inmigrantes se han convertido en un problema serio también dentro en la Unión Europea, cuyas autoridades no pueden otorgar permisos de residencia para los matrimonios múltiples. Más precisamente, la persona originaria de un país donde dichas relaciones son legales - al recibir la permanencia - está autorizada para traer únicamente a un esposo o esposa. El país miembro decide entonces si, en tales casos, se debería de otorgar permisos de residencia a los hijos de un sólo matrimonio o a todos los hijos. Los problemas de esta clase afectan particularmente fuerte a Francia, donde la minoría musulmana, que acepta la poligamia, llega a unos 5 millones de personas. ${ }^{37}$

Las convenciones de los Derechos Humanos, obra de las civilizaciones occidentales, no estipulan la libertad en cuanto a la constitución de las diversas formas de matrimonio y familia. Si bien, de acuerdo con el derecho internacional privado, existe la obligación de reconocer los matrimonios legalmente contraídos en otro país, las cláusulas de orden público de las democracias europeas usualmente consideran que las relaciones poligámicas no son compatibles con las reglas su ordenamiento jurídico interno. ${ }^{38}$ La falta de protección legal condena a muchas personas que viven en las relaciones no-monogámicas a sufrir todo tipo de discriminación, falta de seguridad social, estigmatización y exclusión social. ${ }^{39}$

Según alguos, la prohibición de la bigamia va en contra de la idea misma de la neutralidad del Estado. Sostienen que la libertad personal es un valor universal y la única barrera que pudiera restringirla es la regla de "no hacerle daño al otro". Argumentan que el marco jurídico no puede sustentarse únicamente en un típo definido de moraliad. Además, las eventuales consecuencias legales de la bigamia se consideran mínimas, ya que la ley no prohíbe, en realidad, la convivencia dentro de un círculo de personas más grande. ${ }^{40}$

Además de ello, es cada vez más difundida y habitual la idea de que "el hecho de reservar el sello sagrado a los matrimonios heterosexuales, mientras que, en el mismo nivel, ya se ofertan las uniones civiles (no obstante, distintas al matrimonio) a las personas homosexuales, sirve únicamente para excluir a estos últimos de las instituciones sociales básicas." 41 De hecho, el criterio de "dos sexos distintos"

\footnotetext{
37 Idem.

38 D. Bunikowski, Podstawowe kontrowersje dotyczace ingerencji prawa w sferę moralności, Toruń 2010, 368-369 pp.

39 D. Jabłoński, L. Ostasz, Zarys wiedzy o rodzinie, mał̇eństwie, kohabitacji i konkubinacie: perspektywa antropologii kulturowej i ogólnej, Olsztyn 2011, 237-238 pp.

40 W. Sadurski, Neutralność moralna prawa. (przyczynek do teorii prawa liberalnego), [en:] "Państwo i Prawo" 1990, vol. 7, 40-41 pp.

41 W. Eksridge, Equality Practice Civil Union and Future of Gay Rights, New York-London 2003, p. 156.
} 
como requisito obligado para contraer matrimonio puede ser visto, con toda la razón, como una práctica claramente discriminatoria.

Las constituciones modernas que rigen en los países democráticos manifiestamente prohiben la discriminación por cualquier razón, incluidas las preferencias sexuales de las personas. El Tratado de Amsterdam (1997) estipula que la Unión Europea debe emprender las acciones necesarias con tal de eliminar la marginación y la exclusión por motivos de sexo, raza u origen étnico, religión o credo, minusvalía, edad u orientación sexual (art. 2, ley 7). El país que viole la regla de la "no discriminación sexual" puede ser, incluso, suspendido en sus derechos de membresía.

El proceso de melting pot suscita muy diversos dilemas prácticos que representan, a su vez, serios desafíos para los juzgados. Desde la perspectiva de las cuestiones anteriormente debatidas, vale la pena recordar un caso examinado por el tribunal polaco. Se trataba de los problemas derivados de los tradicionales matrimonios culturales contraídos por los ciudadanos polacos de origen romaní. En este sentido, en la tradición romaní se secuestra a las mujeres con tal de casarse con ellas; no obstante, lo anterior, en muy raras ocasiones, tiene que ver con la violencia. Por lo general, los jóvenes planifican escaparse juntos, lo cual equivale per se a contraer matrimonio. Asimismo, esta forma de "boda" tradicional es muy popular entre los residentes y ciudadnos de origen romaní, a pesar de que, desde la perspectiva del derecho polaco, no tiene ningún efecto legal. En el caso anteriormente mencionado, se trataba de un hombre de 18 años de edad que se casó, de esta manera tradicional, con una mujer de 15 años. Poco después, tuvieron un hijo. De acuerdo con lo estipulado por la ley de relaciones familiares, los romaníes, a la hora de casarse, no cumplían los requisitos de edad. Además, como en el caso hubo relaciones sexuales con una menor de 15 años, se violó también el derecho penal; podía tratarse, incluso, de un caso de pedofilia. Al respecto, en 2007, los romaníes polacos difundieron una declaración especial, en la cual apelaron al respeto hacia su tradición. Demostraban que uno de sus elementos esenciales es la práctica del matrimonio con mujeres a edades muy tempranas, alegando, a su vez, a la ley polaca sobre las minorías culturales que obliga a tomar en cuenta sus especificidades y particularidades. ${ }^{42}$ Vale la pena mencionar aquí que, en el caso discutido, el tribunal polaco, por primera vez, hizo uso de la institución de cultural defence. Se puede pronosticar que, a futuro, casos de este tipo serán cada vez más numerosos.

\footnotetext{
42 S. Sykuna, Filozofia prawa a multikulturalizm - studium pewnego przypadku, [en:] D. Bunikowski, K. Dobrzeniecki (coords.), op. cit., 193-195 pp.
} 


\section{Conclusiones}

Todas las situaciones anteriormente discutidas demuestran una suerte de colisión o choque entre las reglas pertenecientes a los muy diversos sistemas normativos: de usos y costumbres, la religión o la moral. Está clara la confrontación entre la ley y los imperativos culturales muy arraigados en la tradición de una minoría nacional o étnica. En la mayoría de estos casos, el multiculturalismo hace más difícil la convivencia pacífica y puede convertirse, incluso, en una amenaza a la seguridad. Vale la pena subrayar que, si bien la idea de la tolerancia y la "apertura" hacia lo otro y lo diferente son parte de la civilización occidental y, a la vez, reflejo del humanismo; no obstante, en pleno siglo XXI, no debería de permitirse ni tolerarse las prácticas bárbaras y crueles, ni siquiera alegando a los principios religiosos. Es cierto que la libertad de culto es uno de los Derechos Humanos y, en el mismo sentido, la religión es un valor cultural y social. Sin embargo, en las democracias contemporáneas, además de existir la libertad de elegir la religión de su preferencia, también existe la libertad de no elegir ninguna. Asimismo, la libertad de religión no puede convertirse en una libertad absoluta y férrea. A la hora de resolver los conflictos y las tensiones existentes, el diálogo inter-cultural resulta necesario. Por tanto, con cada vez mayor frecuencia se advierte sobre la necesidad de definir el multiculturalismo no tanto como "multi", sino más bien como "inter". El interculturalismo implica traspasar, impregnar, trasladar, sobreponer y cruzar unas culturas con otras. ${ }^{43}$ Pone el énfasis en la coexistencia, en los encuentros y los reencuentros, así como en la cooperación entre los grupos que representan diferentes sistemas de valores, creencias, distintos lenguajes, tradiciones y experiencias colectivas. Dicho de otro modo, el interculturalismo pone el énfasis en la importancia fundamental del diálogo y la negociación entre las culturas, y no su fusión en una suerte de "mezcolanza" homogénea y, en cierto modo, acultural. ${ }^{44}$

\section{Legal culture in Europe and multiculturalism. Challenges to democracy in the $21^{\text {st }}$ century}

\section{Summary}

The article deals with the legal implications of multiculturalism, in the context of globalization and the "clash of civilizations". From a Euro-

43 W. Welsh, Transkulturowość. Nowa koncepcja kultury, [en:] R. Kubicki (coord.), Filozoficzne konteksty koncepcji rozumu transwersalnego. Wokót koncepcji Wolfganga Welscha, Poznań 1998, s. 203.

44 M. Ratajczyk, Podróż ku międzykulturowości, „Kultura - Historia - Globalizacja” 2014, nr 15, p. 209. 
pean-democratic perspective, we analyze several practical dilemmas - the consequence of a "collision" between diverse normative systems: their respective standards, views of morality, religion, costumes, among others. Confronting many different and, sometimes, competing values - inevitable in pluralistic societies - represents a huge challenge for government authorities and, particularly, lawmakers. The idea of multiculturalism which, until now, has been an inherent element of European legal systems, nowadays faces a serious crisis. In this context, there is an urgent need to implement appropriate policies and laws able to protect diverse cultural groups and to ensure efficient instruments, in order to eliminate the unwanted effects of multiculturalism, such as extremism and terrorism.

Key words: multiculturalism, globalization, cultural defence, religious fundamentalism, legal culture, the clash of civilizations

Palabras claves: multiculturalismo, globalización, defensa cultural, fundamentalismo religioso, cultura jurídica, el choque de civilizaciones

\section{Bibliografia}

Bagby P., Pojęcie kultury, [en:] F. Adamski (coords), Człowiek. Wychowanie. Kultura. Wybór tekstów, Cracovia 1993.

Bauman Z., Plynna nowoczesność, Cracovia 2006.

Bauman Z., La Globalización: Consecuencias Humanas, Fondo de Cultura Económica, México 2001.

Bauman Z., Zindywidualizowane społeczeństwo, Gdańsk 2008.

Bunikowski D., Podstawowe kontrowersje dotyczace ingerencji prawa w sfere moralności, Toruń 2010.

Bront J., Nowacka B., Różnorodność zwiazków matżeńskich na świecie, Krynica Morska 2008.

Breczko A., O potrzebie redefinicji pojęć „matżeństwo” $i$ „rodzina” we wspótczesnym pluralistycznym świecie (w kontekście rozważań na temat zwiazków partnerskich), [en:] "Miscellanea Historico-Iuridica" 2014, vol. XIII.

Breczko A., Wielokulturowość jako źródto dylematów moralnoprawnych w demokratycznych państwach prawa, [en:] M. Andruszkiewicz, A. Breczko, S. Oliwniak (coords), Filozoficzne i teoretyczne zagadnienia demokratycznego państwa prawa, Białystok 2015 .

A. Breczko, S. Oliwniak, Biopolitics, ethics and the culture of lawfulness. Implications for the next generation?, [en:] H. Kury, S. Redo, E. Shea (coords), Women and Children as Victims and Offenders, Background, Prevention, Reintegration. Suggestions for Succeeding Generations, Springer 2015.

Dawson C., Istota kultury, [en:] F. Adamski (coords), Człowiek. Wychowanie. Kultura. Wybór tekstów, Cracovia 1993. 
Drewniak A., Wartości perfekcjonistyczne z perspektywy prawa, [en:] S. Wronkowska (coords), Polska kultura prawna a proces integracji europejskiej, Cracovia 2005.

Eksridge W., Equality Practice Civil Union and Future of Gay Rights, New York-London 2003.

Fukuyama F., Wielki wstrzas. Natura ludzka a budowa porzadku spolecznego, Varsovia 2000.

Giddens A., Socjologia, Varsovia 2012.

Golding M.P., The Cultural Defence, "Ratio Juris" 2002, vol. 15, núm. 2.

Gordon N.A., The Implications of Memetics for the Cultural Defence, "Duke Law Journal" 2001, vol. 50 .

Huntington S., Zderzenie cywilizacji i nowy ksztalt ladu światowego, Varsovia 2006.

Jabłoński D., Ostasz L., Zarys wiedzy o rodzinie, małżenstwie, kohabitacji i konkubinacie: perspektywa antropologii kulturowej i ogólnej, Olsztyn 2011.

Jastrzębski B., O funkcjach ideałów w zasadach demokratycznego państwa prawa, [en:] A. Kryniecka (coords), Dzisiejsze znaczenie ideałów, Varsovia 2015.

Kiersznowski Ł., Demokracja a wielokulturowość - postawa państwa demokratycznego wobec wspótczesnych zmian społecznych, "Drohiczyński Przegląd Naukowy. Wielokulturowe Studia Drohiczyńskiego Towarzystwa Naukowego" 2014, núm. 6.

Lewandowska A., Nieprzeciętność a formy matżeństw $i$ demokracja, [en:] M. Szyszkowska, A. Rossmanith (coords), Nieprzeciętność. Dylemat wolności, Varsovia 2013.

Ratajczyk M., Podróż ku międzykulturowości, „Kultura - Historia - Globalizacja” 2014, núm. 15.

Sadurski W., Neutralność moralna prawa. (przyczynek do teorii prawa liberalnego), [en:] "Państwo i Prawo" 1990, vol. 7.

Shell S., The Liberal Case Against Gay Marriage, "The Public Interest" 2004, núm. 156.

Sykuna S., Filozofia prawa a multikulturalizm - studium pewnego przypadku, [en:] D. Bunikowski, K. Dobrzeniecki (coords), Pluralizm prawny, tradycja, transformacje, wyzwania, Toruń 2009.

Toffler A., Trzecia fala, Varsovia 1986.

Tokarczyk R., Wspótczesne kultury prawne, Varsovia 2012.

Welsh W., Transkulturowość. Nowa koncepcja kultury, [en:] R. Kubicki (coords), Filozoficzne konteksty koncepcji rozumu transwersalnego. Wokól koncepcji Wolfganga Welscha, Poznań 1998.

Dr hab. Anetta Breczko, prof. UwB; Zakład Filozofii Prawa i Etyki Prawa, Katedra Teorii Prawa i Filozofii Prawa, Wydział Prawa, Uniwersytet w Białymstoku; breczko@uwb.edu.pl

Doctorante Agata Breczko; Instituto de Investigaciones Económicas, Universidad Nacional Autónoma de México; agata.breczko@comunidad.unam.mx 